\title{
Classification of hydrogen-bond motives in crystals of NH-pyrazoles: a mixed empirical and theoretical approach
}

\author{
Ibon Alkorta, ${ }^{a}$ José Elguero, $^{a}{ }$ Concepción Foces-Foces ${ }^{b}$, and Lourdes Infantes ${ }^{b}$ \\ a Instituto de Química Médica, CSIC, Juan de la Cierva, 3. E-28006 Madrid, Spain \\ ${ }^{b}$ Departamento de Cristalografía, Instituto de Química-Física Rocasolano, CSIC, Serrano 119, \\ E-28006 Madrid, Spain \\ E-mail: iqmbe17@iqm.csic.es
}

To Professor Félix H. Cano, our friend and teacher, in memoriam

\begin{abstract}
A search in the Cambridge Structural Database for NH-pyrazoles lacking other hydrogen-bond donor and acceptor sites, has identified 49 compounds that crystallize in 47 structures forming dimers (16), tetramers (13), trimers (8), hexamers (1) and catemers (10) using $\mathrm{N}-\mathrm{H} \cdots \mathrm{N}$ hydrogen bonds. These structures have been classified in two classes (dimers and tetramers vs. trimers and catemers) using the accessible surface to an atom with good results. The method has been extended to new pyrazoles by means of theoretical calculations (B3LYP/6-31G*) of the geometry of the monomers. Aspects like the conformation of phenyl substituents, the additivity of substituent effects and the buttressing effect have been approached theoretically.
\end{abstract}

Keywords: Pyrazoles, crystal structures, hydrogen bonds, molar refractivity, DFT calculations, Cambridge Structural Database

\section{Introduction}

$\mathrm{N}$-Unsubstituted pyrazoles although less relevant biologically than $N$-unsubstituted imidazoles are much more interesting in what concerns the $\mathrm{N}-\mathrm{H} \cdots \mathrm{N}$ hydrogen bonds (HBs) present in their crystals (the HBs of the remaining NH-azoles, 1,2,3- and 1,2,4-triazoles, tetrazoles and their benzo derivatives are all either of the "pyrazole-type" or the "imidazole-type"). The 1,3disposition of the nitrogen atoms in imidazoles lead exclusively to the formation of chains, catemers, ${ }^{1}$ while the 1,2-disposition in pyrazoles lead to at least five motives (Scheme 1, the Etter/Bernstein graph set descriptors are given for each motif). ${ }^{2,3}$. 


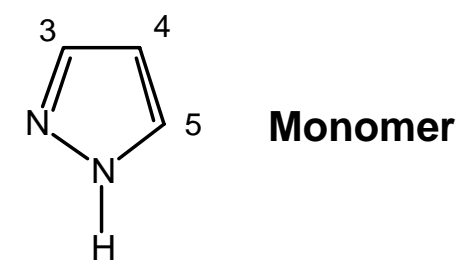

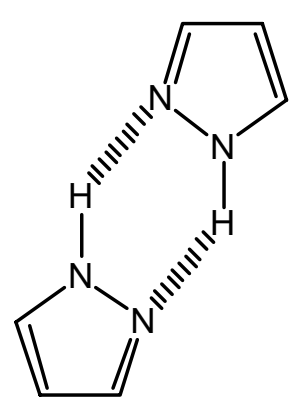

Dimer
$\mathbf{R}_{2}^{2}(6)$

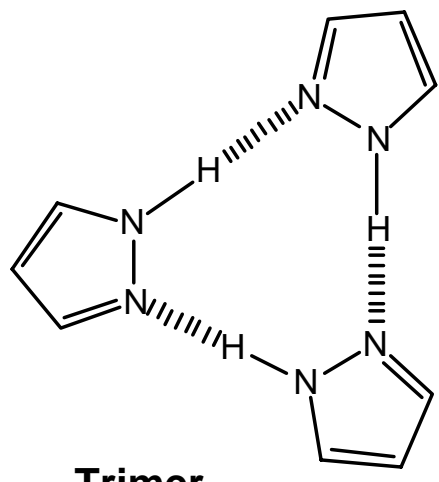

Trimer

$\mathbf{R}_{3}^{3}(9)$

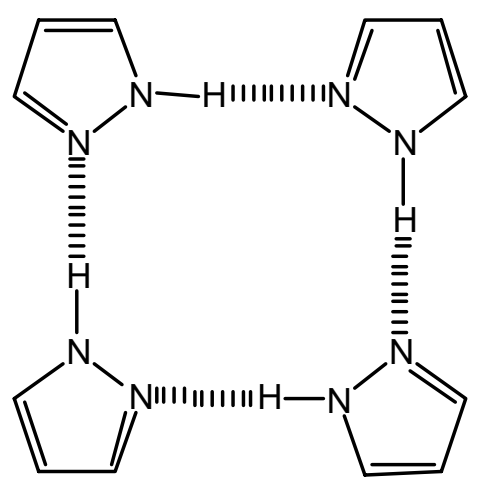

Tetramer $\mathbf{R}_{4}^{4}(\mathbf{1 2})$<smiles>c1cn2[n+](c1)Cn1ccc[n+]1Cn1ccc[n+]1Cn1ccc[n+]1Cn1ccc[n+]1C[n+]1cc[n+]([nH]1)C2</smiles>

Hexamer

$\mathbf{R}_{6}^{6}(\mathbf{1 8})$

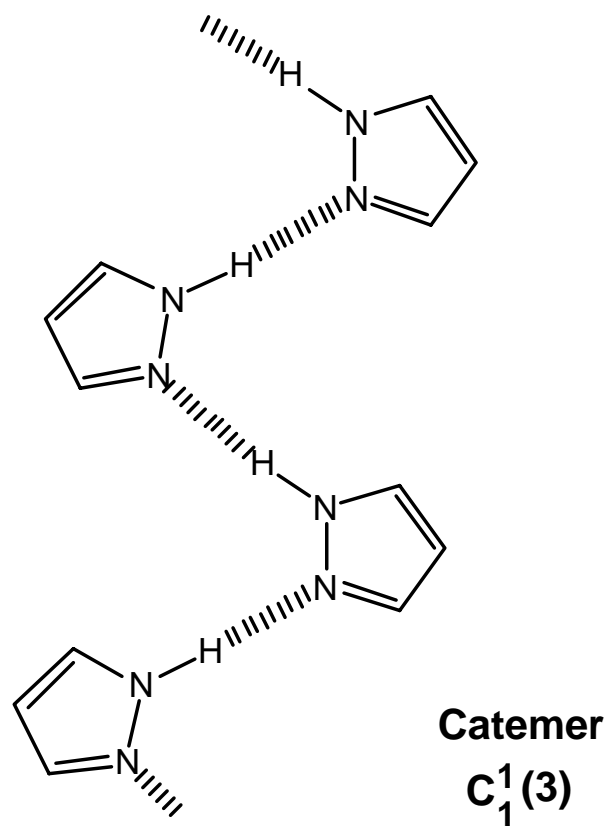

Is there any relationship between the nature of the $C$-substituents in the monomer and the hydrogen bond pattern present in the crystal? In the year 2000, Foces-Foces, Alkorta and Elguero published a paper ${ }^{4}$ on this problem where two important conclusions were reached. The first and most important one was that to make sense, the structures must be grouped in two classes: i) trimers and catemers; ii) dimers and tetramers (hexamers were not known at that time). The second one was that the first family consists of NH-pyrazoles with small substituents at positions 
3 and 5 (substituents at position 4 were found irrelevant) while the second set corresponds to bulky ones. The best descriptor for the substituent size was the molar refractivity, $M R$ (according to the IUPAC, the molar refractivity is the molar volume corrected by the refractive index. It represents size and polarizability of a fragment or molecule). ${ }^{5}$ Four years later, Infantes and Motherwell reexamined this problem from another crystallographic point of view. ${ }^{6}$ The two sets of $\mathrm{NH}$-pyrazoles ${ }^{4,6}$ differ not only because new structures have been published but because the second authors eliminate $\mathrm{HB}$ acceptors groups like $\mathrm{CO}_{2} \mathrm{R}$ and NO. Both sets included TEHQAY, 17, ${ }^{4,6}$ compound that we have omitted because it shows an intramolecular hydrogen bond between the NH and the ortho methoxy group. More recently, Fayos, Infantes and Cano used a neural network for predicting the secondary structure in NH-pyrazoles. 7

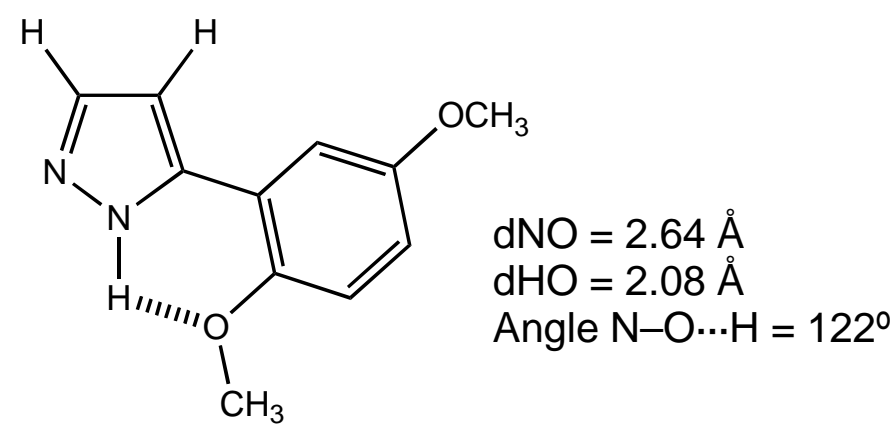

\section{TEHQAY}

Infantes and Motherwell used the sum of the normalized accessible surface $\mathrm{F}$ of both nitrogen atoms (after the NH proton has been removed), Sum-F, to classify the pyrazoles in the two groups previously mentioned with considerable success. ${ }^{6}$ According to the convention used by these authors, F1 is the accessible surface for $\mathrm{N} 1$ adjacent to $\mathrm{R}^{5}$ and $\mathrm{F} 2$ for $\mathrm{N} 2$ adjacent to $\mathrm{R}^{3}$.

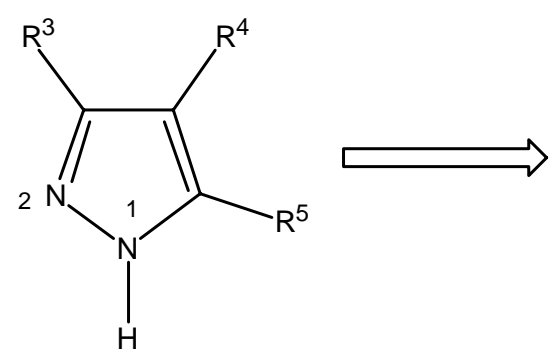

F2

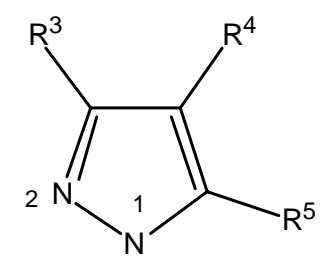

F1

The first model can be used for new pyrazoles to predict the structural group in which they should crystallize provided the $M R$ value of the substituent is known. This is a severe limitation and the authors of the first publication have to propose new values of $M R$ to explain the HB motif. ${ }^{4}$ The second model is not predictive because the calculation of sum-F needs the structure to be known. ${ }^{6}$

The aim of the present work is to establish if the sum-F determined using the geometry of the monomer calculated theoretically can be used to predict the HB pattern of a new NH- 
pyrazole. We will discuss our findings in the following order. First we will describe the methods used, then we will examine successively i) the consistency of the sum-F values obtained from the crystal structure and from the theoretically calculated monomer; ii) the problem of the additivity of the effect of substituents at positions 3 and 5; iii) the problem of phenyl and other aromatic substituents; iv) the possible existence of a buttressing effect of the substituent at position 4 when at positions 3 and/or 5 are other bulky groups, and v) test the discriminating power of sumF.

\section{Results and Discussion}

\section{Computational details}

Calculations of the geometries of $\mathrm{NH}$-pyrazole monomers have been calculated at the hybrid DFT method, B3LYP/6-31G* ${ }^{8,9}$ using the facilities provided by the Gaussian 03 package. ${ }^{10} \mathrm{~A}$ frequency analysis has been carried out to verify that all the structures are minima. The program RPluto $^{11}$ has been used to calculate the accessible surface of an atom (for more details, see reference 6). A completely accessible free atom has $\mathrm{F}=1.00$, and a completely inaccessible atom has $\mathrm{F}=0.00$.

\section{Analysis of CSD structures}

To understand the reason why the number of structures (47) and the number of compounds (49) differ we have to remember that NH-pyrazoles with different substituents at positions 3 and 5 present annular tautomerism. ${ }^{12}$ In some cases both tautomers are present in the crystal either with the proton of the hydrogen bond localized in one nitrogen atom or dynamically shifting between both $\mathrm{N}$ atoms. Besides, there are some cases of polymorphism, that have the opposite effect.

In Table 1 we have summarized all the NH-pyrazoles reported in the CSD (version 5.26, updated February and May 2005) ${ }^{13}$ that we have used for the discussion. The $\beta$-naphthyl substituent will be assimilated to a phenyl ring in the calculations of substituent effects in the case of compounds MAFVOF (45) and MAFWAS (46).

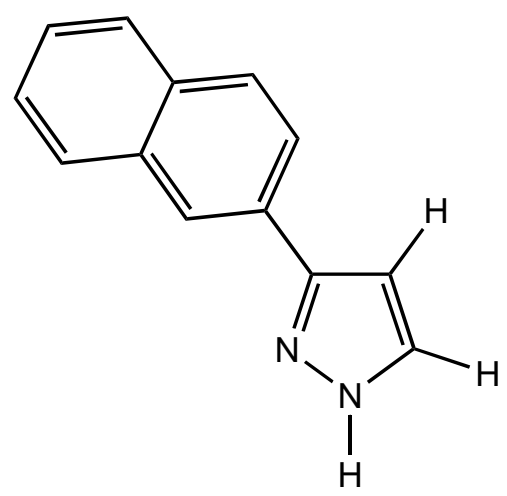

MAFVOF 45

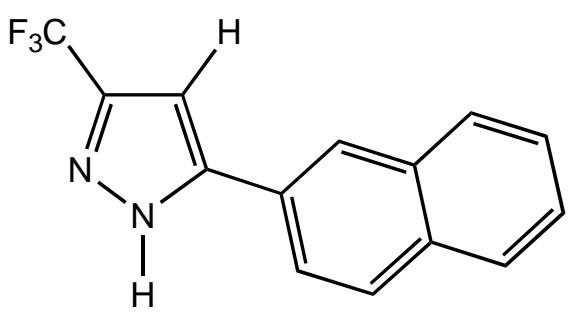

MAFWAS 46 
Table 1. NH-pyrazoles

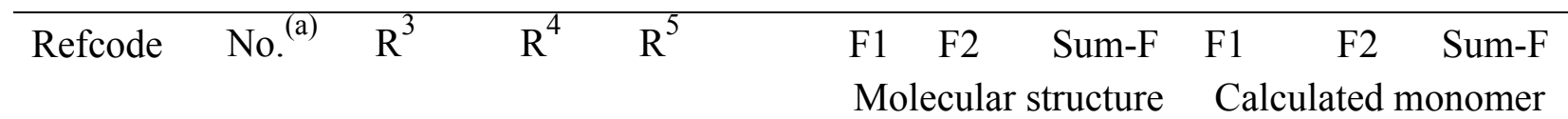

\begin{tabular}{|c|c|c|c|c|c|c|c|c|c|c|}
\hline \multicolumn{11}{|c|}{ Dimers } \\
\hline ALACEV & --- & $\mathrm{C}_{6} \mathrm{H}_{5}$ & $\mathrm{H}$ & Pyridyl & 0.22 & 0.21 & 0.43 & & & \\
\hline ATOWAH & --- & $p \mathrm{PhOPh}$ & $\mathrm{H}$ & $p \mathrm{PhOPh}$ & 0.21 & 0.19 & 0.40 & & & \\
\hline CAMFUS & --- & $\mathrm{Ar}$ & $\mathrm{H}$ & $\mathrm{Ar}$ & 0.21 & 0.20 & 0.41 & & & \\
\hline CIQHIT & --- & $\mathrm{OSiR}_{3}$ & $\mathrm{H}$ & $\mathrm{CH}_{3}$ & 0.25 & 0.07 & 0.32 & & & \\
\hline EDIXOE & --- & $\mathrm{R}^{(\mathrm{b})}$ & $\mathrm{H}$ & $\mathrm{R}^{(\mathrm{b})}$ & 0.15 & 0.26 & 0.41 & & & \\
\hline HEHTUJ & 23 & $\mathrm{CH}_{3}$ & $\mathrm{NO}_{2}$ & $\mathrm{H}$ & 0.30 & 0.27 & 0.57 & & & \\
\hline LADBEX & 15 & $\mathrm{C}_{6} \mathrm{H}_{5}$ & $\mathrm{Br}$ & $\mathrm{C}_{6} \mathrm{H}_{5}$ & 0.20 & 0.19 & 0.39 & & & \\
\hline MAFWAS & 46 & $\mathrm{CF}_{3}$ & $\mathrm{H}$ & $\mathrm{C}_{10} \mathrm{H}_{7}$ & 0.19 & 0.25 & 0.44 & & & \\
\hline NIBFIN & --- & $\mathrm{Ar}$ & $\mathrm{H}$ & $\mathrm{H}$ & 0.30 & 0.21 & 0.51 & & & \\
\hline OBIZAA & 36 & $\mathrm{CF}_{3}$ & $\mathrm{H}$ & Thienyl & 0.21 & 0.24 & 0.45 & & & \\
\hline UFIXAI & --- & $\mathrm{CH}_{2} \mathrm{CN}$ & $\mathrm{H}$ & $\mathrm{Ar}$ & 0.20 & 0.22 & 0.42 & & & \\
\hline VEHCOA & 21 & $\mathrm{H}$ & $\mathrm{NO}_{2}$ & $\mathrm{Si}\left(\mathrm{CH}_{3}\right)_{2}$ & 0.17 & 0.32 & 0.49 & & & \\
\hline WILBAU & 12 & $t \mathrm{Bu}$ & $\mathrm{NO}_{2}$ & $t \mathrm{Bu}$ & 0.19 & 0.18 & 0.37 & & & \\
\hline WILBEY & 14 & $\mathrm{C}_{6} \mathrm{H}_{5}$ & $\mathrm{NO}_{2}$ & $\mathrm{C}_{6} \mathrm{H}_{5}$ & 0.19 & 0.24 & 0.43 & & & \\
\hline YEYQOI & --- & $i \operatorname{Pr}$ & $\mathrm{H}$ & $i \operatorname{Pr}$ & 0.16 & 0.19 & 0.35 & & & \\
\hline YULNUO & 10 & $t \mathrm{Bu}$ & $\mathrm{H}$ & $t \mathrm{Bu}$ & 0.17 & 0.17 & 0.34 & 0.18 & 0.17 & 0.35 \\
\hline & & & & Tetramers & & & & & & \\
\hline DIRKOE & 16 & $\mathrm{CF}_{3}$ & $\mathrm{H}$ & $\mathrm{CF}_{3}$ & 0.24 & 0.23 & 0.47 & 0.25 & 0.23 & 0.48 \\
\hline ESUJOR & --- & $\mathrm{CF}_{3}$ & $\mathrm{H}$ & $\mathrm{C}_{6} \mathrm{H}_{5}$ & 0.20 & 0.25 & 0.45 & & & \\
\hline $\begin{array}{l}\text { HUMLUW } \\
01\end{array}$ & --- & $\mathrm{H}$ & $\mathrm{H}$ & $\mathrm{C}_{6} \mathrm{H}_{5}$ & 0.20 & 0.30 & 0.50 & & & \\
\hline $\begin{array}{l}\text { HUMLUW } \\
01\end{array}$ & --- & $\mathrm{C}_{6} \mathrm{H}_{5}$ & $\mathrm{H}$ & $\mathrm{H}$ & 0.30 & 0.20 & 0.50 & 0.29 & 0.21 & 0.50 \\
\hline LADBIB & 13 & $\mathrm{C}_{6} \mathrm{H}_{5}$ & $\mathrm{H}$ & $\mathrm{C}_{6} \mathrm{H}_{5}$ & 0.21 & 0.21 & 0.42 & 0.21 & 0.21 & 0.42 \\
\hline LIYGOP & 41 & $\mathrm{CH}_{3}$ & $\mathrm{Br}$ & $\mathrm{C}_{6} \mathrm{H}_{5}$ & 0.19 & 0.26 & 0.45 & & & \\
\hline LIYGOP & 44 & $\mathrm{C}_{6} \mathrm{H}_{5}$ & $\mathrm{Br}$ & $\mathrm{CH}_{3}$ & 0.26 & 0.19 & 0.45 & & & \\
\hline МЕРНРY & 40 & $\mathrm{CH}_{3}$ & $\mathrm{H}$ & $\mathrm{C}_{6} \mathrm{H}_{5}$ & 0.21 & 0.26 & 0.47 & & & \\
\hline МЕРНРY & 43 & $\mathrm{C}_{6} \mathrm{H}_{5}$ & $\mathrm{H}$ & $\mathrm{CH}_{3}$ & 0.26 & 0.21 & 0.47 & & & \\
\hline PAHKIT & --- & $\mathrm{H}$ & $\mathrm{H}$ & $t \mathrm{Bu}$ & 0.16 & 0.34 & 0.50 & & & \\
\hline QAMQEA & 22 & $\mathrm{CH}_{3}$ & $\mathrm{H}$ & $t \mathrm{Bu}$ & 0.17 & 0.27 & 0.44 & 0.17 & 0.26 & 0.43 \\
\hline QOFWOX & --- & $\mathrm{H}$ & $t \mathrm{Bu}$ & $i \operatorname{Pr}$ & 0.16 & 0.32 & 0.48 & 0.17 & 0.32 & 0.49 \\
\hline QOFWUD & --- & $\mathrm{H}$ & $t \mathrm{Bu}$ & $\mathrm{CH}_{2} t \mathrm{Bu}$ & 0.16 & 0.31 & 0.47 & & & \\
\hline QOFXAK & --- & $\mathrm{Ar}$ & $t \mathrm{Bu}$ & $\mathrm{H}$ & 0.31 & 0.25 & 0.56 & 0.29 & 0.26 & 0.55 \\
\hline SAKQAX & --- & Mes & $\mathrm{H}$ & $\mathrm{H}$ & 0.29 & 0.19 & 0.48 & & & \\
\hline
\end{tabular}




\begin{tabular}{|c|c|c|c|c|c|c|c|c|c|c|}
\hline XAHBUD & --- & $\mathrm{H}$ & $\mathrm{Br}$ & $\begin{array}{l}\text { Ad } \\
\text { Hexamers }\end{array}$ & 0.17 & 0.31 & 0.48 & 0.15 & 0.31 & 0.46 \\
\hline HUMLUW & --- & $\mathrm{C}_{6} \mathrm{H}_{5}$ & $\mathrm{H}$ & $\begin{array}{c}\mathrm{H} \\
\text { Trimers }\end{array}$ & 0.30 & 0.21 & 0.51 & 0.29 & 0.21 & 0.50 \\
\hline $\begin{array}{l}\text { DASXEA1 } \\
0\end{array}$ & 6 & $\mathrm{CH}_{3}$ & $\mathrm{H}$ & $\mathrm{CH}_{3}$ & 0.26 & 0.26 & 0.52 & 0.27 & 0.26 & 0.53 \\
\hline FITQAA & 18 & $\mathrm{H}$ & $\mathrm{CH}_{3}$ & $\mathrm{CH}_{3}$ & 0.26 & 0.31 & 0.57 & & & \\
\hline GOQXIT & 5 & $\mathrm{H}$ & $\mathrm{Br}$ & $\mathrm{H}$ & 0.30 & 0.29 & 0.59 & & & \\
\hline HEHVAR & 20 & $\mathrm{H}$ & $\mathrm{NO}_{2}$ & $\mathrm{CH}_{3}$ & 0.25 & 0.31 & 0.56 & & & \\
\hline HOQHUQ & 2 & $\mathrm{H}$ & $\mathrm{CH}_{3}$ & $\mathrm{H}$ & 0.31 & 0.30 & 0.61 & 0.31 & 0.29 & 0.60 \\
\hline PAMTAY & 25 & $\mathrm{C}_{6} \mathrm{H}_{5}$ & $\mathrm{Br}$ & $\mathrm{H}$ & 0.29 & 0.23 & 0.52 & 0.29 & 0.21 & 0.50 \\
\hline RIKNOO & 38 & $\mathrm{NO}_{2}$ & $\mathrm{H}$ & $\mathrm{H}$ & 0.29 & 0.25 & 0.54 & 0.29 & 0.25 & 0.54 \\
\hline WIKZUL & 4 & $\mathrm{H}$ & $\mathrm{NO}_{2}$ & $\begin{array}{l}\mathrm{H} \\
\text { Catemers }\end{array}$ & 0.30 & 0.29 & 0.59 & & & \\
\hline FITQEE & 7 & $\mathrm{CH}_{3}$ & $\mathrm{CH}_{3}$ & $\mathrm{CH}_{3}$ & 0.28 & 0.26 & 0.54 & & & \\
\hline GOQXOZ & 9 & $\mathrm{CH}_{3}$ & $\mathrm{Br}$ & $\mathrm{CH}_{3}$ & 0.27 & 0.26 & 0.53 & & & \\
\hline LETNAZ & 8 & $\mathrm{CH}_{3}$ & $\mathrm{NO}_{2}$ & $\mathrm{CH}_{3}$ & 0.26 & 0.26 & 0.52 & & & \\
\hline MAFVOF & 45 & $\mathrm{C}_{10} \mathrm{H}_{7}$ & $\mathrm{H}$ & $\mathrm{H}$ & 0.30 & 0.22 & 0.52 & & & \\
\hline NEZMOU & 39 & $\mathrm{H}$ & $\mathrm{H}$ & Ad & 0.17 & 0.30 & 0.47 & 0.17 & 0.32 & 0.49 \\
\hline NEZMOU & 42 & Ad & $\mathrm{H}$ & $\mathrm{H}$ & 0.30 & 0.17 & 0.47 & 0.31 & 0.16 & 0.47 \\
\hline NIBFIN & --- & $\mathrm{Ar}$ & $\mathrm{H}$ & $\mathrm{H}$ & 0.30 & 0.22 & 0.52 & & & \\
\hline NOPRUF & 3 & $\mathrm{H}$ & Ad & $\mathrm{H}$ & 0.29 & 0.32 & 0.61 & & & \\
\hline OMEKEW & --- & $\mathrm{H}$ & $\mathrm{C}_{6} \mathrm{H}_{5}$ & $\mathrm{H}$ & 0.30 & 0.30 & 0.60 & 0.31 & 0.29 & 0.60 \\
\hline PYRZOL02 & 1 & $\mathrm{H}$ & $\mathrm{H}$ & $\mathrm{H}$ & 0.29 & 0.32 & 0.61 & 0.32 & 0.29 & 0.61 \\
\hline UHENIE & --- & $\mathrm{H}$ & $\mathrm{H}$ & $\mathrm{C}_{6} \mathrm{H}_{5}$ & 0.20 & 0.31 & 0.51 & 0.22 & 0.32 & 0.54 \\
\hline
\end{tabular}

(a) These numbers correspond to those of reference 4. ${ }^{\text {(b) }}$ 9-Fluorenylmethyl.

Consistency of the sum-F values obtained from the crystal structure and from the theoretically calculated monomer

An examination of Table 1 shows that the agreement is excellent. The largest difference (0.03) corresponds to UHENIE, 5-phenylpyrazole, which will be discussed in another section together with other aryl or heteroaryl substituents. It is safe to assume that no larger deviations will be found and thus that we can mix crystallographic and theoretically calculated $\mathrm{F}$ values. We have gathered in Table 2 a series of pyrazoles we have calculated for this work. 
Table 2. Calculated NH-pyrazoles

\begin{tabular}{llllll}
\hline $\mathrm{R}^{3}$ & $\mathrm{R}^{4}$ & $\mathrm{R}^{5}$ & $\mathrm{~F} 1$ & $\mathrm{~F} 2$ & Sum-F \\
\hline $\mathrm{CH}_{3}$ & $\mathrm{H}$ & $\mathrm{H}$ & 0.292 & 0.270 & 0.562 \\
$\mathrm{H}$ & $\mathrm{H}$ & $\mathrm{CH}_{3}$ & 0.258 & 0.316 & 0.574 \\
$t \mathrm{Bu}$ & $\mathrm{H}$ & $\mathrm{H}$ & 0.292 & 0.188 & 0.480 \\
$\mathrm{H}$ & $\mathrm{H}$ & $t \mathrm{Bu}$ & 0.166 & 0.316 & 0.482 \\
$t \mathrm{Bu}$ & $t \mathrm{Bu}$ & $t \mathrm{Bu}$ & 0.140 & 0.148 & 0.288 \\
$\mathrm{CF}_{3}$ & $\mathrm{H}$ & $\mathrm{H}$ & 0.292 & 0.248 & 0.540 \\
$\mathrm{H}$ & $\mathrm{H}$ & $\mathrm{CF}_{3}$ & 0.230 & 0.318 & 0.548 \\
$\mathrm{H}$ & $\mathrm{H}$ & $\mathrm{NO}_{2}$ & 0.228 & 0.310 & 0.538 \\
$\mathrm{NO}_{2}$ & $\mathrm{H}$ & $\mathrm{NO}_{2}$ & 0.224 & 0.250 & 0.474 \\
$\mathrm{~F}$ & $\mathrm{H}$ & $\mathrm{H}$ & 0.296 & 0.306 & 0.602 \\
$\mathrm{H}$ & $\mathrm{H}$ & $\mathrm{F}$ & 0.282 & 0.316 & 0.598 \\
$\mathrm{~F}$ & $\mathrm{H}$ & $\mathrm{F}$ & 0.282 & 0.316 & 0.600 \\
$\mathrm{Cl}$ & $\mathrm{H}$ & $\mathrm{H}$ & 0.296 & 0.288 & 0.584 \\
$\mathrm{H}$ & $\mathrm{H}$ & $\mathrm{Cl}$ & 0.268 & 0.314 & 0.582 \\
$\mathrm{Cl}$ & $\mathrm{H}$ & $\mathrm{Cl}$ & 0.290 & 0.286 & 0.576 \\
$\mathrm{Br}$ & $\mathrm{H}$ & $\mathrm{H}$ & 0.296 & 0.286 & 0.582 \\
$\mathrm{H}$ & $\mathrm{H}$ & $\mathrm{Br}$ & 0.264 & 0.316 & 0.580 \\
$\mathrm{Br}$ & $\mathrm{H}$ & $\mathrm{Br}$ & 0.290 & 0.282 & 0.572 \\
$\mathrm{Si}\left(\mathrm{CH}_{3}\right)_{3}$ & $\mathrm{H}$ & $\mathrm{H}$ & 0.294 & 0.196 & 0.490 \\
$\mathrm{H}$ & $\mathrm{H}$ & $\mathrm{Si}\left(\mathrm{CH}_{3}\right)_{3}$ & 0.194 & 0.312 & 0.506 \\
$\mathrm{Si}\left(\mathrm{CH}_{3}\right)_{3}$ & $\mathrm{H}$ & $\mathrm{Si}\left(\mathrm{CH}_{3}\right)_{3}$ & 0.194 & 0.200 & 0.394 \\
\hline & & & & & \\
\hline
\end{tabular}

A statistical analysis of the data of Tables 1 and 2 (the data of symmetrically substituted compounds DASXEA10, YULNUO, DIRKOE and of 3-nitropyrazole RIKNOO were also used in the second regression) gave the following average F effects per substituent see Table 3. 3,4,5Tri-tert-butylpyrazole was not used in the calculation due to buttressing effects (see below, discussion on this topic). 
Table 3. Average effects: top results are from Table 1 while bottom results came from Table 2

\begin{tabular}{llll}
\hline Substituent & $\mathrm{R}^{3}$ on $\mathrm{F} 2$ & $\mathrm{R}^{5}$ on $\mathrm{F} 1$ & $M R$ \\
\hline $\mathrm{H}$ & 0.31 & 0.30 & 0.10 \\
$\mathrm{CH}_{3}$ & 0.26 & 0.26 & 0.56 \\
$i \mathrm{Pr}, \mathrm{CH}_{2} t \mathrm{Bu}, \mathrm{Bu}, \mathrm{Ad}$ & 0.18 & 0.17 & $1.96(t \mathrm{Bu})$ \\
$\mathrm{CF}_{3}$ & 0.24 & 0.24 & 0.50 \\
$\mathrm{Ar}$ & 0.21 & 0.20 & $2.54\left(\mathrm{C}_{6} \mathrm{H}_{5}\right)$ \\
& & & \\
$\mathrm{H}$ & 0.31 & 0.29 & 0.10 \\
$\mathrm{CH}$ & 0.26 & 0.26 & 0.56 \\
$t \mathrm{Bu}$ & 0.18 & 0.17 & $1.96(t \mathrm{Bu})$ \\
$\mathrm{CF}$ & 0.24 & 0.24 & 0.50 \\
$\mathrm{NO}_{2}$ & 0.25 & 0.23 & 0.74 \\
$\mathrm{~F}$ & 0.31 & 0.28 & 0.09 \\
$\mathrm{Cl}$ & 0.29 & 0.28 & 0.60 \\
$\mathrm{Br}$ & 0.28 & 0.28 & 0.89 \\
$\mathrm{Si}\left(\mathrm{CH}_{3}\right)_{3}$ & 0.20 & 0.19 & 2.50 \\
\hline
\end{tabular}

The effects calculated from experimental geometries (upper part) and from theoretical geometries of the monomers (bottom part) are almost identical. Note also that the effect of $\mathrm{R}^{3}$ on $\mathrm{F} 2 \approx$ the effect of $\mathrm{R}^{5}$ on $\mathrm{F} 1$ : the pyrazole geometry after removing the NH is near "symmetric" $\left(C_{2 v}\right)$.

Since in reference 4 the molar refractivity was used for the same purpose than $\mathrm{F}$, we have plotted in Figure $1 M R$ against F (average of the values of Table 3). Although the correlation is not good $\left(\mathrm{r}^{2}=0.75\right)$, the tendency is the same, which could explain the success using $M R$ to classify NH-pyrazoles into two families. 


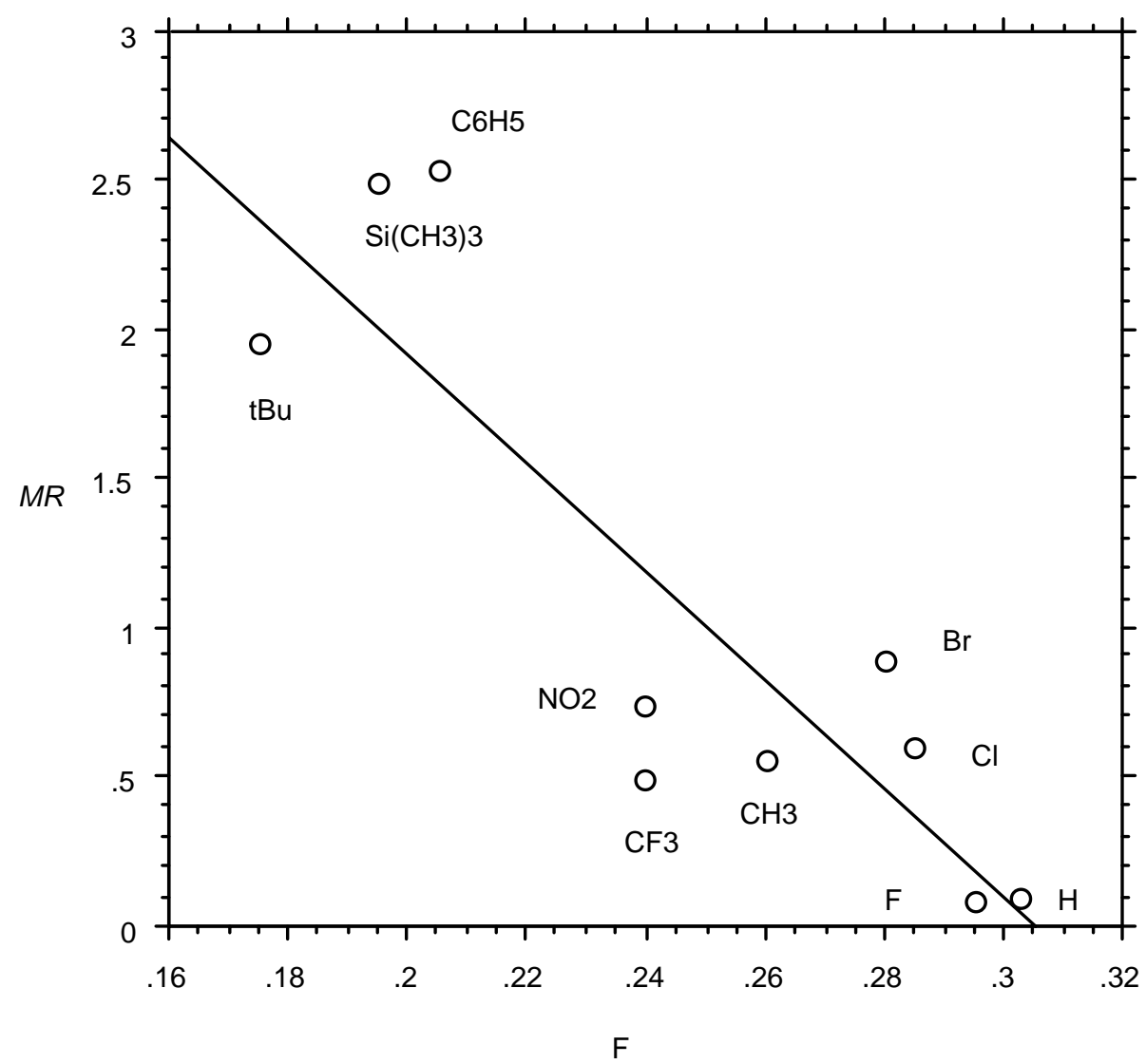

Figure 1. Plot of $M R$ vs. F for different substituents.

\section{Problem of the phenyl and other aromatic substituents}

The phenyl group (and other aromatic and heteroaromatic rings) is one of the less isotropic substituents and its $\mathrm{F}$ value depends on the dihedral angle between itself and the pyrazole ring. It is not surprising that the 3(5)-phenylpyrazole (sum-F $=0.50$ ) crystallized as tetramers (HUMLUW01), 3-phenylpyrazole (sum-F = 0.51) as hexamers (HUMLUW) and 5-phenylpyrazole (sum-F $=0.51$ ) crystallize as catemers (UHENIE). Its 4-bromo derivative (3-phenyl-4bromo-pyrazole, PAMTAY, sum-F $=0.52$ ) crystallize as trimers. We will see later on that sum-F $=0.51$ is the borderline between both classes of secondary structures.

We have calculated for the 3-phenyl and 5-phenylpyrazole monomers the values of sum-F corresponding to different dihedral angles (from 0 to $90^{\circ}$ in $15^{\circ}$ intervals, values like $0^{\circ}, 15^{\circ}$, etc. are exact values without error):

- 3-Phenylpyrazole: $0^{\circ}$ (minimum, 0.50$), 15^{\circ}(0.50), 30^{\circ}(0.51), 45^{\circ}(0.53), 60^{\circ}(0.55), 75^{\circ}$ (0.56), $90^{\circ}(0.56)$. In the hexamer HUMLUW, sum-F $=0.51$ for an average torsion angle of $13^{\circ}$. In the tetramer HUMLUW01, sum-F $=0.50$ for an average torsion angle of $15^{\circ}$

- 5-Phenylpyrazole: $0^{\circ}(0.54), 15^{\circ}(0.54), 27.8^{\circ}$ (minimum, 0.55$), 30^{\circ}(0.55), 45^{\circ}(0.56)$, $60^{\circ}(0.57), 75^{\circ}(0.57), 90^{\circ}(0.57)$. In the catemer UHENIE, sum-F $=0.51$ for a torsion angle of 


\section{$17.9^{\circ}$}

- 3,5-Diphenylpyrazole: minimum energy conformation, 3-phenyl, 6.3 ${ }^{\circ}, 5$-phenyl, $27.7^{\circ}$ (average $17.0^{\circ}$ ), sum-F $=0.42$. In the tetramer LADBIB there are two independent molecules but the $\mathrm{NH}$ proton being disordered there is no difference between 3- and 5-phenyl groups, the average torsion angles of the two independent molecules are $25.7^{\circ}$ and $13.1^{\circ}$, and the sum-F is 0.42 (Table 1).

A last comment about aryl groups: in our statistical treatment of the upper part of Table 3 , we have considered together groups such as phenyl, $p$-tolyl, $\beta$-naphthyl, 2-pyridyl and 2-thienyl without observing any significant deviation. This observation also increases the predictive power of the model to other aryl/heteroaryl groups.

\section{Problem of the additivity of the effect of substituents at positions $\mathbf{3}$ and $\mathbf{5}$}

From the values of Table 3 it is possible to calculate any 3,5-disubstituted derivative. In general, the additivity is verified (independence of the F1 and F2 substituent effects). The largest deviations are found for 46 (3-trifluoromethyl-5-(2'-naphthylpyrazole, $\Delta$ sum-F $=-0.01$, the general effect of an aryl group, 0.21, has been used) and WILBAU (3,5-di-tert-butyl-4nitropyrazole, $\Delta$ sum- $\mathrm{F}=+0.02$ ).

\section{Possible existence of a buttressing effect of the substituent at position 4 when at positions 3 and/or 5 is another bulky group}

It has been assumed in the two previous publications, ${ }^{4,6}$ that a substituent at position 4 does not play any role on the HB motives of NH-pyrazoles. In Table 1, there are several compounds that only differ in the $\mathrm{R}^{4}$ substituent, the effect of $\mathrm{R}^{4}$ on $\mathrm{F}$ is $\leq|0.03|$, with no clear tendency about the sign. We think it would be better if we approach this problem from the theoretical geometry of the monomers. To this aim, we selected the following pyrazoles (Scheme 2). All the values correspond to Fs calculated using the theoretical geometry of the monomer (remember that $\mathrm{F}$ increases when the $\mathrm{N}$ atom becomes more accessible and decreases when it become more inaccessible). Compounds 47-50 have been calculated specially for this section. 


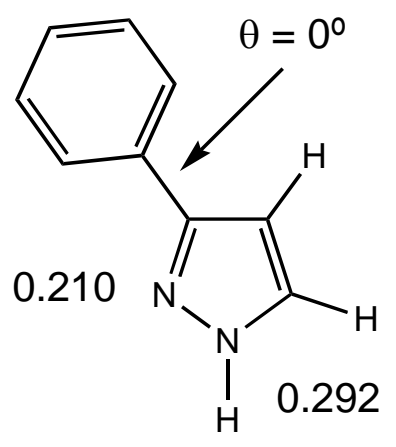

[HUMLUW]

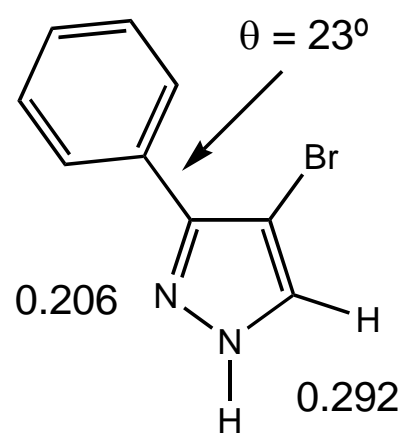

[PAMTAY]

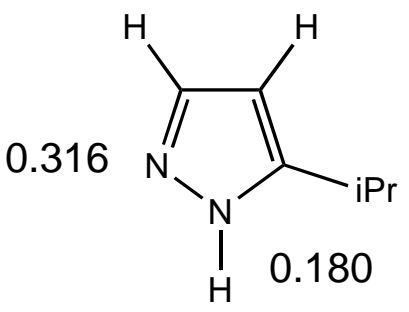

47

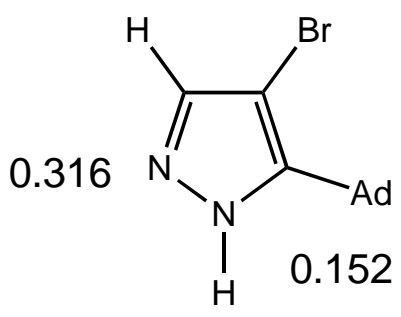

[XAHBUD]

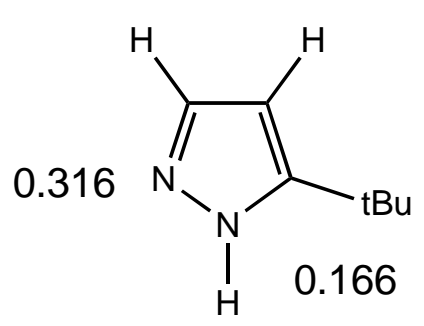

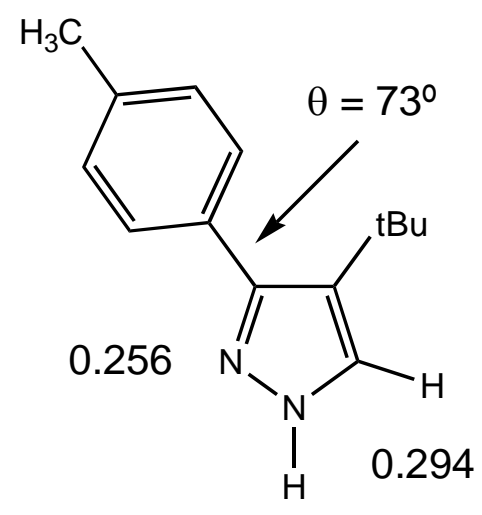

[QOFXAK]<smiles>[R16]OCCCC</smiles>

[QOFWOX]

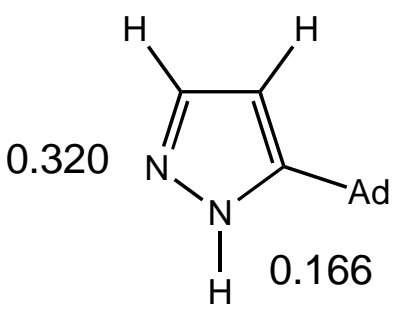

[NEZMOU]

0.188

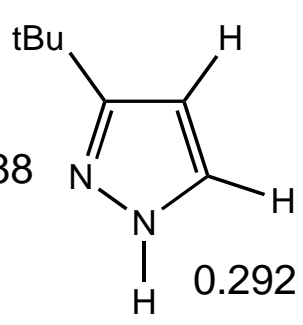

48
49

0.148

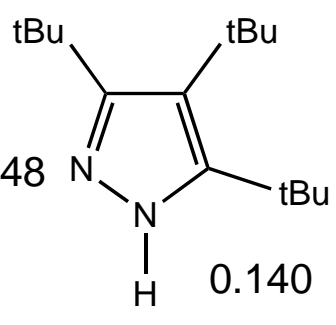

50

Scheme 2

In the 3-phenyl series, a 4-bromo substituent twists the phenyl ring $23^{\circ}$ and makes it a little more sterically demanding (-0.004). In contrast, the 4-tert-butyl group increases the torsion 
angle $\theta$ and simultaneously decreases considerably the size of the phenyl group $(+0.046)$. This will have important consequences on the packing mode of QOFXAK. In a certain sense, this is an anti-buttressing effect.

Normal although weak buttressing effects are observed in QOFWOX and in XAHBUD (iPr and 1-adamantyl -0.008 and -0.014 more "bulky"). When 3,4,5-tris-tert-butyl-pyrazole 50 is compared with the monosubstituted derivatives 48 and 49 (Table 2), the buttressing effects are considerable: $3-t \mathrm{Bu}-0.026$ and $5-t \mathrm{Bu}-0.040$.

\section{Testing the discriminating power of sum-F}

As a test, two pyrazoles crystallizing as tetramers, reported in reference 1 with the numbers 24 and 37 but never published, were calculated $(24, \mathrm{~F} 1=0.17, \mathrm{~F} 2=0.21$, sum-F $=0.38 ; 37, \mathrm{~F} 1=$ $0.17, \mathrm{~F} 2=0.25$, sum-F $=0.42$ ). The complete data of Table 1 is represented graphically in Figure 2.

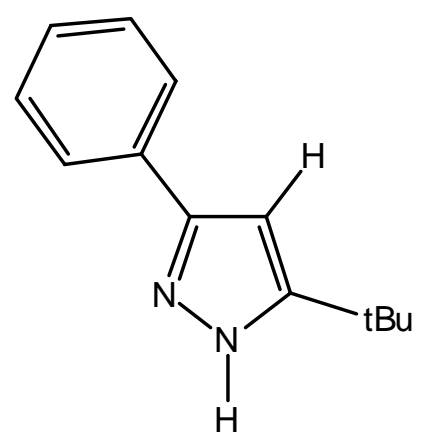

24

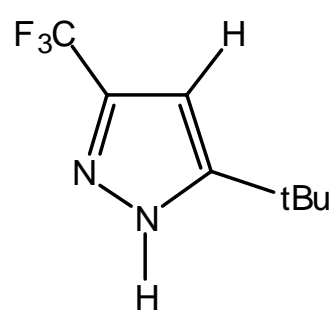

37

In the horizontal axis of Figure 2, there are only two values. Class 0 is that of pyrazoles crystallizing in dimers or tetramers while class 1 corresponds to trimers and catemers. There is only an hexamer, HUMLUW, that having a sum-F $=0.51$ we have not classified, i.e. we have not decided if hexamers are more alike to trimers than to tetramers. In the vertical axis are the sum-F values of Table 1 (plus 24 and 37). Since in several cases two different pyrazoles have the same sum-F value, the number of points (black squares) is inferior to the total number of pyrazoles (50: 16 dimers, 15 tetramers, 8 trimers, 1 hexamer and 10 catemers). Pyrazoles 24 and 37 were correctly classified. We have not differentiated between subclasses within a class because they are overlapping to a large extent.

The frontier is situated at sum-F $=0.51$. For pyrazoles having these values the classification is uncertain and both classes can be found; these are good candidates to present polymorphism. 


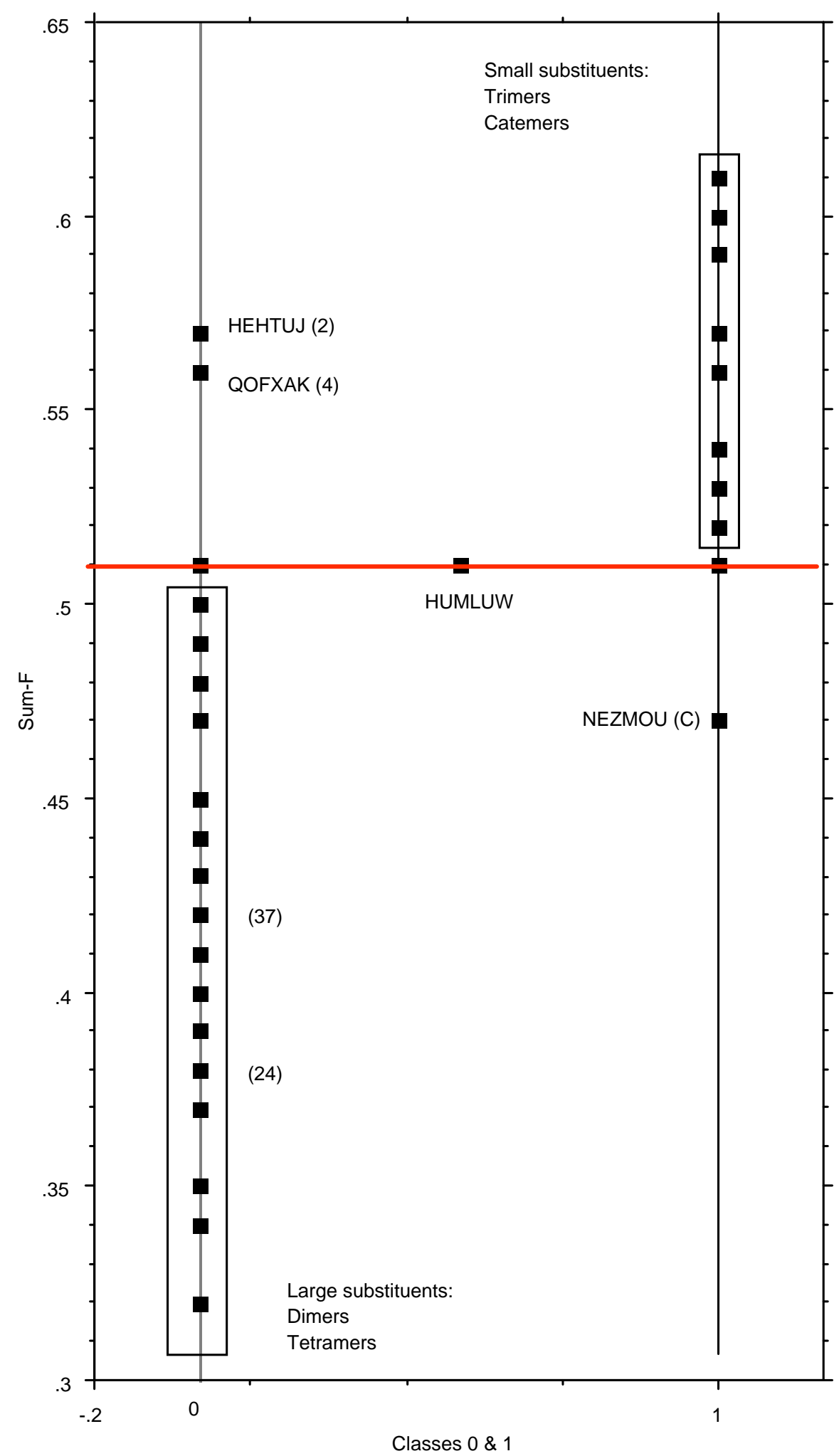

Figure 2. Representation of the discrimination of NH-pyrazoles using sum-F (2: dimer; 4: tetramer; $\mathrm{C}$ : catemer). 
Why are there exceptions? Of the 50 examples, there are three clear outliers: 3-methyl-4nitropyrazole (HEHTUJ, 23) which crystallizes as a dimer while sum-F predict a trimer or catemer; 3-p-tolyl-4-t-butylpyrazole (QOFXAK) which crystallizes as a tetramer while sum-F predict a trimer or catemer, and 3-(1'-adamantyl)pyrazole (NEZMOU, 42) which crystallizes as a catemer while sum-F predict a dimer or a tetramer. These exceptions correspond to two situations: the first one corresponds to small substituents that can crystallize in one of the more compact secondary structures (trimer, catemer) and that crystallize in one of the less compact structures: the HEHTUJ dimer and the QOFYAK tetramer. More surprising is the case of NEZMOU that accommodate the large 1-adamantyl substituent in the compact catemer structure. The notion of "compactness" was discussed in reference 4.

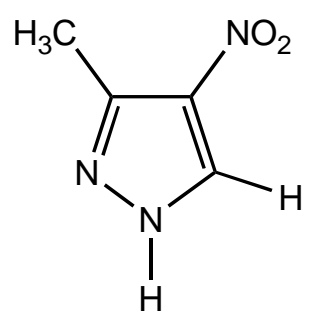

HEHTUJ

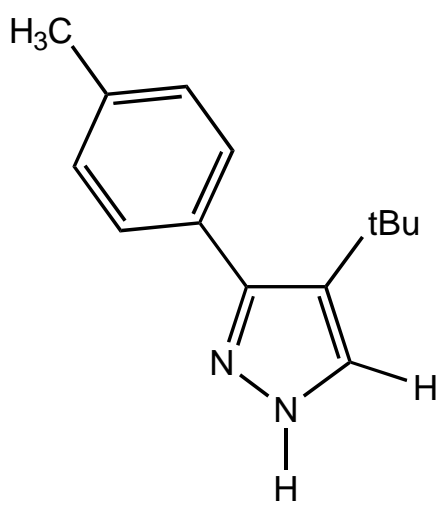

QOFXAK

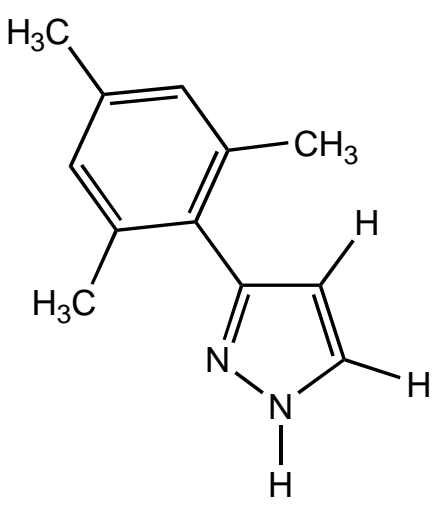

SAKQAX

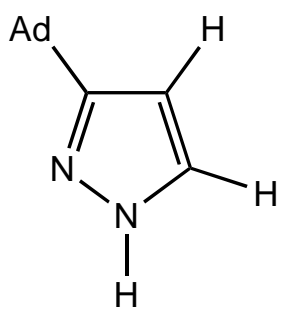

NEZMOU

The case of QOFXAK is interesting: it is one of the rare tetramers where the centroids of the four pyrazole rings are planar $\left(\psi=90^{\circ}\right.$, see 4 for the definition of $\psi$; no example of this situation was known in 2000); the second one is SAKQAX that was correctly classified as a tetramer ( sum-F $=0.48$ ). The experimental phenyl/pyrazole torsion angle is $79^{\circ}$ (compare with $\theta$ $=73^{\circ}$, Scheme 2). As explained before, this made the 3 -aryl ring less demanding but still sum-F $=0.56$ (X-ray) or 0.55 (theory) (Table 1) well above the dividing line of 0.51 reported in Figure 2. An examination of the structure of the tetramer shows stabilizing intermolecular hydrogen bonds between pyrazole $\mathrm{C}(5)-\mathrm{H}$ and the centroids of the aryl rings of adjacent molecules (C$\mathrm{H} \cdots \pi)$. This is the extra-stabilization that could explain the anomaly of Figure 2 . In the case of SAKQAX the two ortho methyl groups of the mesityl substituent increases the torsion angle up to $85^{\circ}$.

The anomaly of NEZMOU could be related to the fact that this catemer is formed by two alternating tautomers, 39 and $\mathbf{4 2}$, i.e. is a $(\mathbf{3 9 + 4 2})_{\mathrm{n}}$ structure. This could reduce the apparent size of the 1-adamantyl substituent (Figure 3). 


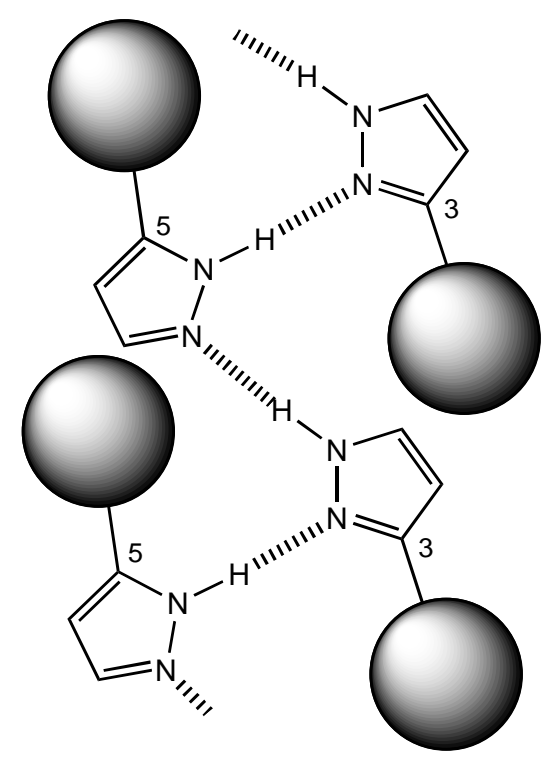

Figure 3. The NEZMOU catemer.

Finally, we must confess that we have no explanation for the HEHTUJ anomaly: simply our model is not refined enough to describe correctly all situations: only most of them.

In conclusion, taking into account our previous papers and the span of time elapsed since the first one (2000-2006), ${ }^{4,6}$ the set of NH-pyrazoles here discussed is much more than a training set. More generally, correlations between atomic or group descriptors on the basis of volumes, areas, etc., have seldom been of any success in crystal structure description and prediction. Few of such correlations have ever withstood the proof of evidence outside the training set used to derive them. Although the crystal potential energy surface is far too complex to explained by simple descriptors alone, we feel that this work provides some advance in our knowledge of crystal packing factors.

\section{Acknowledgements}

This work was supported by DGES/MCyT of Spain.

\section{References}

1. Cammers, A.; Parkin, S. Cryst. Eng. Comm. 2004, 6, 168.

2. (a) Etter, M. C. Acc. Chem. Res. 1990, 23, 120. (b) Etter, M. C.; MacDonald, J.; Bernstein, J. Acta Crystallogr. Sect. B 1990, B46, 256.

3. (a) Bernstein, J.; Etter, M. C.; Leiserowitz, L. "The Role of Hydrogen Bonding in Molecular 
Assemblies" In Structure Correlations; Dunitz, J. D.; Burgi, H.-B. Eds. Vol. 2, VCH: Weinheim, 1994, pp 431-507. (b) Bernstein, J.; Davis, R. E.; Shimoni, L. Chang, N.-L. Angew. Chem, Int. Ed. 1995, 34, 1555.

4. Foces-Foces, C.; Alkorta, I.; Elguero, J. Acta Crystallogr. Sect. B 2000, B56, 1018.

5. Hansch, C.; Leo, A.; Hoekman, D. Exploring QSAR. Hydrophobic, Electronic, and Steric Constants, American Chemical Society, Washington, 1995.

6. (a) Infantes, L.; Motherwell, S. Struct. Chem. 2004, 15, 173. (b) Infantes, L.; Motherwell, S. Chem. Commun. 2004, 1166.

7. Fayos, J.; Infantes, L.; Cano, F. H. Cryst. Growth Design 2005, 5, 191.

8. (a) Becke, A. D. Phys. Rev. A 1988, 38, 3098. (b) Becke, A. D. J. Chem. Phys. 1993, 98, 5648. (c) Lee, C.; Yang, W.; Parr, R. G. Phys. Rev. B 1988, 37, 785.

9. Hariharan, P. A.; Pople, J. A. Theor. Chim. Acta 1973, 28, 213.

10. Gaussian 03, Frisch, M. J.; Trucks, G. W.; Schlegel, H. B.; Scuseria, G. E.; Robb, M. A.; Cheeseman, J. R.; Montgomery, Jr., J. A.; Vreven, T.; Kudin, K. N.; Burant, J. C.; Millam, J. M.; Iyengar, S. S.; Tomasi, J.; Barone, V.; Mennucci, B.; Cossi, M.; Scalmani, G.; Rega, N.; Petersson, G. A.; Nakatsuji, H.; Hada, M.; Ehara, M.; Toyota, K.; Fukuda, R.; Hasegawa, J.; Ishida, M.; Nakajima, T.; Honda, Y.; Kitao, O.; Nakai, H.; Klene, M.; Li, X.; Knox, J. E.; Hratchian, H. P.; Cross, J. B.; Adamo, C.; Jaramillo, J.; Gomperts, R.; Stratmann, R. E.; Yazyev, O.; Austin, A. J.; Cammi, R.; Pomelli, C.; Ochterski, J. W.; Ayala, P. Y.; Morokuma, K.; Voth, G. A.; Salvador, P.; Dannenberg, J. J.; Zakrzewski, V. G.; Dapprich, S.; Daniels, A. D.; Strain, M. C.; Farkas, O.; Malick, D. K.; Rabuck, A. D.; Raghavachari, K.; Foresman, J. B.; Ortiz, J. V.; Cui, Q.; Baboul, A. G.; Clifford, S.; Cioslowski, J.; Stefanov, B. B.; Liu, G.; Liashenko, A.; Piskorz, P.; Komaromi, I.; Martin, R. L.; Fox, D. J.; Keith, T.; Al-Laham, M. A.; Peng, C. Y.; Nanayakkara, A.; Challacombe, M.; Gill, P. M. W.; Johnson, B.; Chen, W.; Wong, M. W.; Gonzalez, C. and Pople, J. A. Gaussian, Inc., Pittsburgh PA, 2003.

11. RPluto, A program for crystal structure visualization, Cambridge Crystallographic Data Centre, Cambridge, 2002 (http://www.ccdc.cam.ac.uk, freely downloadable for noncommercial use).

12. (a) Elguero, J.; Marzin, C.; Katritzky, A. R.; Linda, P. The Tautomerism of Heterocycles, Academic Press: New York, 1976. (b) Minkin, V. I.; Garnovskii, A. D.; Elguero, J.; Katritzky, A. R.; Denisko, O. V. Adv. Heterocycl. Chem. 2000, 76, 157.

13. Allen, F. H. Acta Crystallogr. Sect. B 2002, 58, 380. 